\title{
The Graduate Tax when Education is a Signal
}

\author{
Russayani Ismail \\ Universiti Utara Malaysia \\ Gareth D. Myles* \\ University of Exeter and Institute for Fiscal Studies
}

July 29, 2015

\begin{abstract}
This paper investigates the effects of a graduate tax when the return to education is uncertain and wages are determined through equilibrium in a labor market with signalling. The consequence of uncertainty is that both ability and initial wealth matter for educational choice. Compared to a constrained first-best the market outcome with uncertainty and signalling results in an inefficiently high number of people entering higher education. Due to the positive wealth effect over-entry is proportionately greater for high-wealth individuals. The graduate tax reduces entry into education so enhances efficiency. However, it has undesirable distributional consequences: low-wealth individuals are deterred from entering education but high-wealth are encouraged. In this respect, the graduate tax has clear failings as a method of financing higher education.
\end{abstract}

Keywords: Higher Education, Uncertainty, Signalling, Graduate Tax

*Corresponding author. Address: Department of Economics, University of Exeter, Exeter, EX4 4PU, UK, gdmyles@ex.ac.uk 


\section{Introduction}

The idea of introducing a tax on graduates has often been proposed as an alternative way of recovering the costs of education. ${ }^{1}$ The basic concept of a graduate tax is that students would not have to pay the up-front cost of their education. Instead, the costs would initially be borne by the government with repayment by graduates through a tax premium during their working lives. If the tax is progressive with the rate linked to income, under such a scheme successful graduates will subsidize the less successful Proponents of the graduate tax argue that it is a fairer method of financing higher education since graduates obtain significant private benefit from education in terms of future higher earnings. It is also regarded as a good method of widening access for those from less privileged backgrounds since it avoids the need to pay up-front fees and provides a degree of insurance against future income uncertainty.

If the returns to education were purely private and certain, and the capital market were perfect, then each individual would assess whether the net benefit of education was positive and the perfect capital market would make the timing of repayment of costs immaterial. In these circumstances there is no need for a policy to assist the less privileged since initial wealth would not be a determinant of educational choice. It is unlikely that the market for education conforms to this description. In practice, the return to education is uncertain since individuals cannot perfectly predict the outcome when making educational choices and imperfect capital markets will impose borrowing restrictions. When education involves the production of human capital a standard argument for the graduate tax is that, due to the risk in the future return to education and imperfect capital markets, there will be under-investment in higher education and too little human capital accumulation. The under-investment will be particularly severe for individuals with less initial wealth who find it harder to borrow. Hence, without a corrective policy entry into higher education will not be at the efficient level. In these circumstances a graduate tax may result in a more efficient level of entry.

The accumulation of human capital is not the only explanation of a positive return to investment in education. Weiss (1995) provides compelling evidence that part of the return to education (perhaps, even the entire return) is determined by the effect of signalling rather than through the accumulation of human capital. Both signalling and uncertainty in returns have implications for the properties of a graduate tax. In particular, when they are present it is no longer clear that private educational decisions will remain publicly rational even though they are privately rational. In the absence of intervention signalling provides an incentive for too many people to choose to undertake higher education: the average product is paid to each worker which, for those on the margin be-

\footnotetext{
${ }^{1}$ It has also been the subject of much discussion in the UK. See, for example, the Financial Times editorial on 9 August 2010. (Available at www.ft.com/cms/s/0/e4bcba5a-a3e2-11df9e3a-00144feabdc0.html.) and the Browne Review of higher education funding in the UK (https://www.gov.uk/government/uploads/system/uploads/attachment_data/file/422565/bis10-1208-securing-sustainable-higher-education-browne-report.pdf).
} 
tween choosing higher education or not, is higher than the marginal product. In these circumstances, the argument in favor of the graduate tax needs a careful reassessment.

The present paper addresses how a graduate tax affects participation in higher education and, hence, the impact of the tax on efficiency. The analysis begins by exploring the implications for the demand for higher education of uncertainty about future wages, and wages are determined through equilibrium in a labor market with signalling as in Spence (1973). We extend the analysis of the graduate tax of García-Peñalosa and Walde (2000) by explicitly modelling intertemporal utility maximization, as in Levhari and Weiss (1974) and Kodde (1986). Our model allows for heterogeneity in ability and initial wealth and, because of signalling (or screening) in the labor market, education acts as a signal to potential employers or is used by potential employers to sort workers according to their unobserved abilities. ${ }^{2}$ It is important to note that in contrast to human capital theory, in the signalling model education does not augment productive capacity. Instead, it is just a process to convey information about the unobservable ability level that existed before any education took place. Consequently, if ability were observable it would be efficient to have no education. When ability cannot be observed the efficient education level trades off the benefit of sorting individuals into occupations (placing the high ability into the occupation which is most socially valuable) against the cost of education. We consider the success of the graduate tax against this second measure of efficiency.

The introduction of the graduate tax is modelled through the government subsidizing higher education costs and taxing successful graduates while maintaining a balanced budget. The results show that uncertainty has important implications for the desirability of a graduate tax. When the return to education is uncertain an individual's initial wealth level has an impact upon educational choice: a high-wealth individual will choose to undertake higher education in circumstance in which a low-wealth individual with the same ability level will not. This positive wealth effect is consistent with the results of Levhari and Weiss (1974) and Kodde (1986). We show that the graduate tax discourages people from choosing higher education even though it provides a subsidy to costs. Since there is over-education without the tax this is a beneficial outcome. However, the graduate tax proves more discouraging to low-wealth individuals than to those with high-wealth, so exacerbates the positive wealth effect. After implementation of the graduate tax proportionately more high-wealth individuals receive higher education. Hence, the graduate tax in conjunction with a subsidy to costs is not a mechanism that provides encouragement for low-wealth

\footnotetext{
${ }^{2}$ Weiss (1995) distinguishes between the signalling model in which the informed (students) move first by choosing an education level and the screening models in which the uninformed (firms) move first by offering contracts. In equilibrium the relationship between wages and education could be the outcome of either students choosing an education programme to signal their ability, or the education level being chosen in response to the relative wage offers of firms, in which case wages would serve to screen workers. Our model corresponds to the signalling interpretation.
} 
individuals to undertake higher education.

These results have important policy implications. If signalling does play a significant role in determining earnings, individuals have an incentive to signal their innate ability and this may cause over-investment in education. The extra supply of educated workers drives down the wage for those with higher education. The uncertainty with regard to future income results in a positive wealth effect but the introduction of a graduate tax still fails to encourage people with high ability but from low-wealth backgrounds to invest in education. Thus, even if the capital market is perfect, when education acts as a signal the introduction of a graduate tax will not be an efficient solution since it will further intensify the problem of over-investment among the wealthy with low ability.

The paper is organized as follows. In Section 2 we present our model of educational choice with signalling. Section 3 explores the division of the population between educational choices and demonstrates the positive wealth effect and excess education result. Section 4 demonstrates the effect of the graduate tax on equilibrium and shows that its effects depend upon wealth level. Section 5 discusses the outcome under alternative assumptions on information structure. Conclusions are provided in Section 6. The proofs of the results are given in the Appendix.

\section{The Model}

Following Levhari and Weiss (1974) and Eaton and Rosen (1980) we model educational choice in a two-period setting. Let $x_{i}^{1}$ and $x_{i}^{2}, i=e, n$, denote consumption in the first- and second-period of life where the subscript $e$ denotes that higher education has been chosen and $n$ that it has not been chosen. Preferences are represented by the time separable expected utility function

$$
E U=U\left(x_{i}^{1}\right)+\delta E\left(U\left(\tilde{x}_{i}^{2}\right)\right),
$$

where $\delta$ measures the degree of time preference. The ${ }^{\sim}$ indicates that secondperiod consumption can be a random variable: first-period consumption is always certain but second-period consumption will depend upon the realization of the educational outcome. We assume that the utility function satisfies standard concavity assumptions and that $\lim _{x_{i}^{t} \rightarrow 0} U^{\prime}\left(x_{i}^{t}\right)=\infty$.

The price of first-period consumption and the price of second-period consumption are both normalized to one. The individual maximizes utility subject to a budget constraint that depends on whether investment in higher education is undertaken or not. A perfect capital market is assumed so each individual can borrow and lend at the same rate of interest, $r{ }^{3}$ Individuals differ in terms of their ability, $a$, and initial wealth, $m$. The level of initial wealth is intended to capture the ease with which an individual can access resources to finance higher education. In a practical interpretation it would be related to the wealth level of the family and the willingness of the family to provide financial support.

\footnotetext{
${ }^{3}$ The consequences of relaxing this assumption are discussed in Section 5.
} 
The distribution of ability and initial wealth in the population is described by the density function $f(a, m)$ with range $\left[a_{\min }, a_{\max }\right] \times\left[m_{\min }, m_{\max }\right]$. Each individual is informed about their own ability before the decision on whether to invest in higher education is made. The level of ability is also the (unobservable) marginal product in employment if higher education is undertaken.

The educational choice of an individual involves either investing in higher education or not investing. The choice that gives the highest level of utility is chosen. An individual who chooses not to invest in higher education works in a non-graduate job in both periods and earn wages $w_{n}^{1}$ and $w_{n}^{2}$ in periods 1 and 2 respectively with certainty. For simplicity, it is assumed that $w_{n}^{1}=w_{n}^{2}=w_{n}$.

An individual who chooses higher education trains in period 1 and works in period 2. An element of uncertainty is introduced by modelling the second period wage, $w_{e}^{2}$, as dependent on the outcome of education. We label the outcome as pass, $p$, or fail, $f .{ }^{4}$ The probability of passing is given by the monotonically increasing function of ability $\pi(a)$ and, hence, the probability of failing by $1-\pi(a)$. Education acts as a signal of ability. Employers can observe the level of education and whether a pass or fail was obtained but not ability or wealth. Therefore, employers pay their workforce according to their education level based on the average product (ability) of the two types (pass and fail). A worker who is a 'fail' will receive wage $w_{f}^{2}$ while a 'pass' will receive wage $w_{p}^{2}$, where $w_{p}^{2}>w_{f}^{2}$. The costs of education consist of a direct cost, $c$, as well as the opportunity cost in terms of forgone earnings in the first period.

Notice that in the signalling model the wage is not a function of individual ability. Instead, it is the probability of passing or failing that depends on ability. Any human capital accumulation associated with education is ignored, so that undertaking education does not increase productivity but just provides a signal of unobservable ability.

\section{Equilibrium without Intervention}

This section determines the educational choices that emerge when there is no government intervention. We first analyze the individual decision problem and then characterize market equilibrium with educational signalling. The inefficiency of the equilibrium is also explored.

From an individual perspective, whether higher education increases the wage as a result of signalling or because of human capital accumulation makes no difference. In either case, an individual will choose to undertake higher education if the expected private marginal benefit exceeds the private marginal cost. If the outcome of education is certain and capital markets are perfect the decision reduces to a present value calculation of lifetime income under the two choices. When individuals are risk averse the presence of uncertainty about the consequences of education affects the investment decision. In this case, initial wealth

\footnotetext{
${ }^{4}$ The labels could equally well refer to different levels of attainment, such as "distinction" and "pass" or "first" and "second". What is important is that the outcome is not known for sure when the investment decision is made.
} 
matters.

Consider the consumption choice of an individual who chooses not to pursue higher education. The intertemporal budget constraint for an individual with initial wealth $m$ is

$$
x_{n}^{1}+\frac{x_{n}^{2}}{1+r}=m+w_{n}+\frac{w_{n}}{1+r} .
$$

The optimal level of first-period consumption then solves

$$
\max _{\left\{x_{n}^{1}\right\}} U^{n}=U\left(x_{n}^{1}\right)+\delta U\left((1+r)\left(m+w_{n}-x_{n}^{1}\right)+w_{n}\right),
$$

which has the necessary condition

$$
U^{\prime}\left(x_{n}^{1}\right)-\delta(1+r) U^{\prime}\left(x_{n}^{2}\right)=0 .
$$

Denote the solution to $(4)$ by $x_{n}^{1}(m)$. The maximum value function for the optimization can then be written

$$
V^{n}(m) \equiv U\left(x_{n}^{1}(m)\right)+\delta U\left((1+r)\left(m+w_{n}-x_{n}^{1}(m)\right)+w_{n}\right) .
$$

If an individual decides to invest in higher education the costs are known with certainty. Hence, the first-period budget constraint can be written as

$$
x_{e}^{1}=m-c-s,
$$

where $s$ is the level of saving. In the second period, the wage depends on the realization of the educational outcome. If the individual achieves a pass, $p$, the budget constraint is

$$
x_{p}^{2}=w_{p}^{2}+(1+r)\left(m-c-x_{e}^{1}\right),
$$

whereas if a fail, $f$, is obtained the second-period budget constraint is

$$
x_{f}^{2}=w_{f}^{2}+(1+r)\left(m-c-x_{e}^{1}\right) .
$$

The assumptions on the utility function ensure that the individual will not choose an intertemporal plan for which second-period consumption is negative for either educational outcome. Using (7) and (8), the expected utility resulting from choosing education is

$$
\begin{aligned}
E U^{e} & =U\left(x_{e}^{1}\right)+\delta \pi(a) U\left(w_{p}^{2}+(1+r)\left(m-c-x_{e}^{1}\right)\right) \\
& +\delta(1-\pi(a)) U\left(w_{f}^{2}+(1+r)\left(m-c-x_{e}^{1}\right)\right) .
\end{aligned}
$$

The necessary condition for the intertemporal allocation of consumption is

$$
U^{\prime}\left(x_{e}^{1}\right)-\pi(a)(1+r) \delta U^{\prime}\left(x_{p}^{2}\right)-(1-\pi(a))(1+r) \delta U^{\prime}\left(x_{f}^{2}\right)=0 .
$$

Solving for $x_{e}^{1}$ generates the consumption function

$$
x_{e}^{1}=x_{e}^{1}(m, a) .
$$


The second-period consumption levels in the two states are obtained by substituting $x_{e}^{1}$ into (7) and (8) to give

$$
x_{k}^{2}=x_{k}^{2}(m, a) \quad k=f, p .
$$

Substituting the consumption levels back into (9) gives

$$
V^{e}(m, a) \equiv U\left(x_{e}^{1}(m, a)\right)+\pi(a) \delta U\left(x_{p}^{2}(m, a)\right)+(1-\pi(a)) \delta U\left(x_{f}^{2}(m, a)\right),
$$

where $V^{e}$ is the maximum value of expected indirect utility for an individual with ability $a$ and wealth $m$ if education is chosen.

The educational choice of an individual is made by comparing utility with, and without, education. If $V^{e}(m, a)>V^{n}(m)$, then an individual with initial wealth $m$ and ability $a$ will choose education. Education will not be chosen if $V^{e}(m, a)<V^{n}(m)$. For given $m$ we call the value of $a$ that implies $V^{e}(m, a)=$ $V^{n}(m)$ the cut-off level of $a$. Since the probability of passing or failing higher education depends on ability, the level of ability matters in determining the choice of higher education. Observe that

$$
\frac{\partial V^{e}(m, a)}{\partial a}=\pi^{\prime}(a) \delta U\left(x_{p}^{2}\right)+\left(1-\pi^{\prime}(a)\right) \delta U\left(x_{f}^{2}\right)>0 .
$$

so, for any given value of $m$, the population partitions with respect to $a$ : those with ability below the cut-off level of $a$ choose no education whereas those with ability above the cut-off choose education.

The effect of the level of initial wealth, $m$, on the choice of education under uncertainty is important from a policy perspective. Many policy interventions have been driven by the belief that those with limited resources are deterred from entering higher education. In the standard model of human capital investment under certainty, for example Becker (1964) and Ben Porath (1967), initial wealth has no effect on educational choice. The separation theorem implies that the consumer maximizes the present value of life-time income in the first period by choosing the level of education, and in the second period decides upon the optimal allocation of wealth over consumption in the two periods. However, the literature relating to the demand for education under uncertainty has noted the presence of income effects (Levhari and Weiss (1974), Kodde (1986), Snow and Warren (1990)) so that initial wealth affects educational choice. Kodde (1986) demonstrates that decreasing absolute risk aversion implies a positive income effect under uncertainty.

We now show that a similar result holds in the signalling model where we interpret a positive income effect to mean that the cut-off level of ability decreases as initial wealth increases. This is stated formally as lemma 1. To state the lemma we write the condition for indifference between education and no education as

$$
\begin{array}{r}
U\left(x_{n}^{1}(m)\right)+\delta U\left((1+r)\left(x_{n}^{2}(m)\right)+w_{n}\right)-U\left(x_{e}^{1}\left(m, a ; w_{f}^{2}, w_{p}^{2}\right)\right) \\
-\pi(a) \delta U\left(x_{p}^{2}\left(m, a ; w_{f}^{2}, w_{p}^{2}\right)\right)-(1-\pi(a)) \delta U\left(x_{f}^{2}\left(m, a ; w_{f}^{2}, w_{p}^{2}\right)\right)=0,
\end{array}
$$


and denote the implied solution of (15) by

$$
a=\alpha\left(m, w_{f}^{2}, w_{p}^{2}\right)
$$

Proposition 1 With decreasing absolute risk aversion the function $\alpha\left(m, w_{f}^{2}, w_{p}^{2}\right)$ is strictly monotonically decreasing in $m$. It is constant when absolute risk aversion is constant, and strictly monotonically increasing in $m$ with increasing absolute risk aversion.

The intuition behind the lemma is that the variance of individual lifetime wealth depends on initial wealth. If initial wealth is high, the additional earnings that an individual receives from education constitute a small portion of total wealth, which reduces the utility consequences of the uncertainty of educational outcome. However, if initial wealth is low, the additional earnings from education will be a larger proportion of the total wealth, thus the outcome of educational uncertainty will have a significant impact. Individuals with low wealth are therefore deterred from choosing higher education by the riskiness of the outcome if absolute risk aversion is higher at lower wealth levels.

We can now use the description of individual choice to characterize equilibrium. Since employers cannot observe the ability level of an individual, a wage is paid based on the average product (ability) of each type (pass or fail). The equilibrium wages for the two types ensure that the educational choices of the population are consistent with those wages. To state the equilibrium conditions, define the function

$$
A\left(m, w_{f}^{2}, w_{p}^{2}\right)=\max \left\{a_{\min }, \min \left\{\alpha\left(m, w_{f}^{2}, w_{p}^{2}\right), a_{\max }\right\}\right\} .
$$

The ability level $A\left(m, w_{f}^{2}, w_{p}^{2}\right)$ is the cut-off ability level at initial wealth $m$ taking into account the limits on ability. The definition of equilibrium then follows:

Definition 2 An equilibrium for the economy is a pair $\left\{w_{f}^{2}, w_{p}^{2}\right\}$ that simultaneously satisfy:

$$
\begin{gathered}
w_{p}^{2}=\frac{\int_{m_{\min }}^{m_{\max }} \int_{A\left(m, w_{f}^{2}, w_{p}^{2}\right)}^{a_{\max }} a \pi(a) f(a, m) d a d m}{\int_{m_{\min }}^{m_{\max }} \int_{A\left(m, w_{f}^{2}, w_{p}^{2}\right)}^{a_{\max }} \pi(a) f(a, m) d a d m} \\
w_{f}^{2}=\frac{\int_{m_{\min }}^{m_{\max }} \int_{A\left(m, w_{f}^{2}, w_{p}^{2}\right)}^{a_{\max }} a(1-\pi(a)) f(a, m) d a d m}{\int_{m_{\min }}^{m_{\max }} \int_{A\left(m, w_{f}^{2}, w_{p}^{2}\right)}^{a_{\max }}(1-\pi(a)) f(a, m) d a d m} .
\end{gathered}
$$

To provide a baseline from which to assess the effects of the graduate tax we now compare the market equilibrium with uncertainty and signalling to the choice of a social planner. The first step is to determine what information structure allows a valid and useful comparison. This is a necessary step because the signalling role of education significantly impacts upon the nature of social 
optimality. To justify this remark, consider being in the situation in which the social planner is able to observe each individual's ability level and credibly convey this information to firms. In this case social planner would be in a position to implement a first-best outcome that would not involve any education. The social planner could directly tell each firm the ability of each worker so education would be unnecessary as a signalling device. In this first-best those individuals with ability below $w_{n}$ would be allocated to the non-graduate job, and those with ability above $w_{n}$ would be allocated to the graduate job with a wage equal to their ability. This outcome would spare the economy the cost of delivering education. As a consequence, any market equilibrium that involves educational signalling will always be inefficient relative to this full-information first-best.

To provide a more informative comparison between what the market achieves and what the social planner can achieve it is necessary to consider the information restrictions faced by the planner. Education has a signalling role because firms are unable to directly observe ability so make use of educational attainment as a substitute for observation. We therefore consider a constrained first-best in which firms hire on the basis of educational attainment but the social planner selects which individuals can enter higher education. This describes a situation in which the planner controls entry to education but cannot control hiring decisions on the labor market. As a practical example of such a situation, until very recent reforms the UK government determined the number of places each university could offer on each course and controlled the educational testing that determined entry to higher education. The justification for employers insisting on using education as a signal is that they do not perceive the planner's assessments of individuals' abilities to be credible so prefer to continue to judge employees on the basis of educational achievement. In this constrained firstbest it is still necessary to have the educational signal in order to direct some individuals into graduate employment but the division of population between educational choices need not match that for the market equilibrium.

The constrained first-best is characterized by the cut-off ability level, $a^{*}$, which is the minimum ability for those who should enter higher education. The value of $a^{*}$ is chosen to maximize the total discounted value of income in the economy net of the costs of higher education. In choosing the cut-off the government takes into account the effect of this choice upon the equilibrium wage. We also assume that the government faces no constraint on redistributing income; thus, we abstract from distributional issues. Due to the power of the government to redistribute, initial wealth does not matter.

The constrained first-best is defined by

$$
\begin{aligned}
a^{*} & \equiv \arg \max \left\{\int_{m_{\min }}^{m_{\max }} \int_{a_{\min }}^{a^{*}} w_{n} f d a d m-c \int_{m_{\min }}^{m_{\max }} \int_{a^{*}}^{a_{\max }} f d a d m\right. \\
& \left.+\frac{1}{1+r}\left[\int_{m_{\min }}^{m_{\max }} \int_{a_{\min }}^{a^{*}} w_{n} f d a d m+\int_{m_{\min }}^{m_{\max }} \int_{a^{*}}^{a_{\max }} a f d a d m\right]\right\} .
\end{aligned}
$$


The necessary condition for choosing $a^{*}$ is

$$
w_{n}+\frac{w_{n}}{1+r}=\frac{a^{*}}{1+r}-c .
$$

Observe that (21) is precisely the condition that would arise in the economy with no risk: it is simply the equality of the discounted value of income in the two cases. This is not surprising, since there is no aggregate risk in the economy. The condition differs from that in (15) in two ways. First, in the market case the marginal individual receives a wage equal to the average productivity. In (21) it is marginal productivity that matters. Second, the market outcome also factors in the risk involved in choosing education, which introduces the dependence of choice on initial wealth.

From this point onward we assume that the preferences satisfy the property of decreasing absolute risk aversion (DARA). Recall from lemma 1 that DARA implies the cut-off value of ability decreases with initial wealth in the market equilibrium. It is therefore possible to determine the nature of the inefficiency of the market equilibrium by comparing the cut-off level of ability for an individual with the minimum level of initial wealth to the constrained first-best cut-off. The outcome of this comparison is described in proposition 3 which shows there will be excessive entry into education as a consequence of educational signalling. Observe, also, that the conclusion is not affected by the probability of success or failure.

Proposition $3 a^{*}>\alpha\left(m, w_{f}^{2}, w_{p}^{2}\right)$ for all $m \in\left[m_{\min }, m_{\max }\right]$.

Combining propositions 1 and 3 permits the degree of over-education to be related to initial wealth level. The cut-off ability level falls with wealth and is always below the constrained first-best level. Hence, the following corollary.

Corollary 4 The excess entry into education is proportionately greater at high initial wealth levels.

This characterization of the market equilibrium has confirmed the nature of the inefficiency. There is always excess entry into education, and this is worst at high initial wealth levels. If a graduate tax is to improve upon this outcome the graduate tax must reduce entry and, preferably, have a stronger effect at high wealth levels. Whether the graduate tax does this is investigated in Section 4. Before proceeding, we demonstrate the results obtained so far using a numerical example that is also used later to illustrate the effects of the graduate tax.

The numerical analysis is based on a logarithmic utility function

$$
U=\log \left(x^{1}\right)+\delta \log \left(\tilde{x}^{2}\right),
$$

a uniform distribution for ability and initial wealth

$$
f(a, m)=\frac{1}{a_{\max }-a_{\min }} \frac{1}{m_{\max }-m_{\min }},
$$


and a probability of success in higher education that is quadratic

$$
\pi(a)=\pi a^{2} .
$$

These function forms are combined with the baseline parameter values $a_{\min }=$ $m_{\min }=0, a_{\max }=m_{\max }=1, w_{n}=0.24, r=0.05, \delta=1, \pi=0.5$, and $c=0.2$.

Using these values, and following (21), the value of the cut-off ability, $a^{*}$, at the constrained first-best is

$$
a^{*}=0.24(2+0.05)+0.2(1+0.05)=0.692 .
$$

The market equilibrium and the constrained first-best are contrasted in Table 1. In this table $p_{e}$ denotes the proportion of the total population educated and $a^{0}=\alpha\left(0, w_{f}^{2}, w_{p}^{2}\right)$. The fact that $a^{0}<a^{*}$ confirms the excessive entry into education because of the signalling effect. The table also shows that excessive education results in lower equilibrium wages for the two educated types.

\begin{tabular}{|l|c|c|c|c|c|}
\hline Scenario & $w_{f}^{2}$ & $w_{p}^{2}$ & $p_{e}$ & $a^{0}$ & $a^{*}$ \\
\hline Market equilibrium & 0.693 & 0.788 & 0.562 & 0.465 & - \\
\hline Constrained first-best & 0.835 & 0.864 & 0.308 & - & 0.692 \\
\hline
\end{tabular}

Table 1: Equilibrium Wage Rates

Using the equilibrium values of $w_{p}^{2}$ and $w_{f}^{2}$, we can provide a graphical representation of the division of the population into those who choose higher education and those who do not. This is given in Figure 1 where the solid line is the locus of cut-off values and the dashed line is the constrained first-best cutoff. The figure shows how the cut-off ability in the market equilibrium decreases as wealth increases. As observed above, this is a consequence of the risk inherent in choosing higher education. The figure also illustrates the substantial degree of excess entry into education.

Table 2 provides an insight into the comparative statics of the equilibrium by determining the effect of an increase in the cost of education. Let $p_{f b}$ be the proportion educated at the constrained first-best and define $I_{o} \equiv \frac{p_{e}}{p_{f b}} . I_{o}$ is an index of over education. The results show that the equilibrium changes in the expected way: the proportion entering education falls as the cost rises and the wages for the educated rise since the mean ability of those educated increases. The index of over-education falls as $c$ increases, so higher cost reduces the proportion choosing education at a faster rate than the constrained first-best proportion falls.

\begin{tabular}{|c|c|c|c|c|}
\hline$c$ & $w_{f}^{2}$ & $w_{p}^{2}$ & $p_{e}$ & $\frac{p_{e}}{p_{f b}}$ \\
\hline 0.2 & 0.693 & 0.788 & 0.562 & 1.825 \\
\hline 0.21 & 0.704 & 0.793 & 0.542 & 1.819 \\
\hline 0.22 & 0.714 & 0.797 & 0.524 & 1.758 \\
\hline
\end{tabular}

Table 2: Education Cost and Wage Rates 


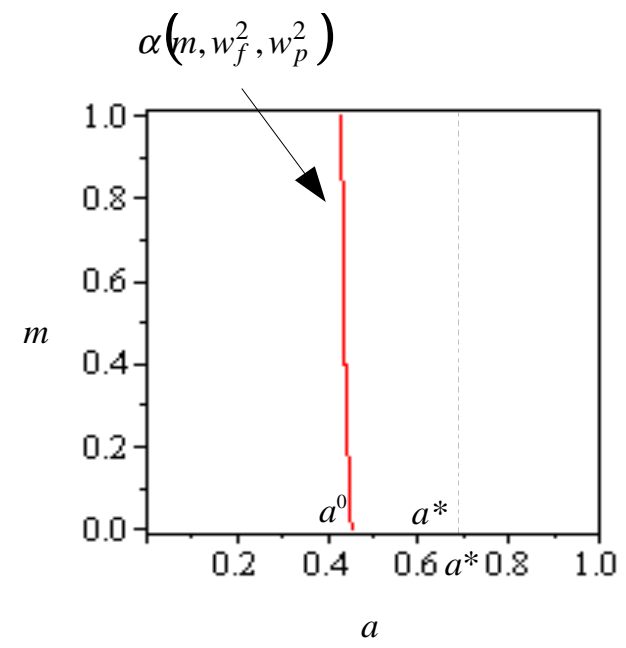

Figure 1: Excess entry into education

This section has considered the individual choice of educational level when education is a signal and has demonstrated that there is a positive wealth effect. The market equilibrium and the constrained first-best have been defined and contrasted. The central result was the demonstration of excess entry into education in the market equilibrium particularly among individuals with high levels of initial wealth. We now investigate whether a graduate tax is a beneficial intervention.

\section{Graduate Tax}

The two key components of the typical graduate tax proposal are a subsidy toward the cost of education financed by a tax premium imposed on graduates. This structure captures the features of the deferred fee system (such as HECs in Australia) and the Graduate Contribution Scheme proposed for the UK where repayment occurs through an additional tax premium when earnings exceed a threshold level. We model a version of the graduate tax proposal in which the tax premium can differ according to income level. ${ }^{5}$ This encompasses the UK proposal as the special case in which the premium on the lowest earning graduates is zero.

The question we address is whether the graduate tax affects educational participation in a beneficial way when education acts as a signal of unobservable ability. With signalling the private return to investment in higher education is larger than the social return for the marginal student since they are rewarded with a wage equal to the mean productivity of their type. We have shown

\footnotetext{
${ }^{5}$ Formally, it varies according to educational outcome. But outcome and income are directly linked in the model.
} 
this results in a greater proportion of the population being educated than is efficient. Furthermore, under the assumption of DARA the over-participation is proportionately greater at high wealth levels. The standard argument in favor of the graduate tax - that it encourages participation - cannot be applied when there is signalling. It is therefore important to examine what effect the graduate tax has with signalling, and whether this is beneficial.

\subsection{Equilibrium}

We assume that the tax rate on the earnings of those who do not choose higher education is zero, so any positive rate is a premium. The tax rate for graduates who pass higher education is denoted $t_{p}>0$ and the rate for those who fail is denoted $t_{f} \geq 0$. The UK proposal described above can be treated as the special case of $t_{f}=0$ by assuming that the threshold for the premium is set above the earnings level of the unsuccessful. All entrants into higher education receive a grant, $g$, to offset educational cost in the first-period of life.

With a graduate tax in operation the first-period budget constraint when education is chosen becomes

$$
x_{e}^{1}=m-c-s+g .
$$

The second-period budget constraint if a pass is obtained is

$$
x_{p}^{2}=\left(1-t_{p}\right) w_{p}^{2}+(1+r)\left(m-c-x_{e}^{1}+g\right),
$$

and in the event of a fail

$$
x_{f}^{2}=\left(1-t_{f}\right) w_{f}^{2}+(1+r)\left(m-c-x_{e}^{1}+g\right) .
$$

Using the second-period budget constraints expected utility can be written as

$$
\begin{aligned}
E U^{e}= & U\left(x_{e}^{1}\right)+\left[\delta \pi ( a ) \left(U \left(\left(1-t_{p}\right) w_{p}^{2}+(1+r)\left(m-c-x_{e}^{1}+g\right)\right.\right.\right. \\
& +(1-\pi(a))\left(U\left(\left(1-t_{f}\right) w_{f}^{2}+(1+r)\left(m-c-x_{e}^{1}+g\right)\right)\right] .
\end{aligned}
$$

This implies a solution for $x_{e}^{1}$ of the form

$$
x_{e}^{1}=x_{e}^{1}\left(m, a, w_{p}^{2}, w_{f}^{2}, g, t_{f}, t_{p}\right) .
$$

The condition for an individual to be indifferent between higher education and no higher education becomes

$$
\begin{gathered}
U\left(x_{e}^{1}\right)+\pi(a) \delta U\left(\left(1-t_{p}\right) w_{p}^{2}+(1+r)\left(m-c+g-x_{e}^{1}\right)\right) \\
+(1-\pi(a)) \delta U\left(\left(1-t_{f}\right) w_{f}^{2}+(1+r)\left(m-c+g-x_{e}^{1}\right)\right) \\
-U\left(x_{n}^{1}\right)-\delta U\left(w_{n}+(1+r)\left(w_{n}-x_{n}^{1}\right)\right)=0 .
\end{gathered}
$$

This indifference condition implies the function, $\hat{\alpha}$, that determines the cut-off ability at each wealth level given the wages and the structure of the graduate tax scheme

$$
a=\hat{\alpha}\left(m, w_{f}^{2}, w_{p}^{2}, g, t_{f}, t_{p}\right)
$$


The graduate tax scheme is assumed to operate with a balanced budget so that the total expenditure on grants must equal the discounted value of tax revenue from the second-period. To state the budget balance condition it is first necessary to account for the range of ability by defining the partition function

$$
\hat{A}\left(m, w_{f}^{2}, w_{p}^{2}, g, t_{f}, t_{p}\right)=\max \left\{a_{\min }, \min \left\{\hat{\alpha}\left(m, w_{f}^{2}, w_{p}^{2}, g, t_{f}, t_{p}\right), a_{\max }\right\}\right\} .
$$

The budget constraint for the programme is therefore

$$
\begin{aligned}
(1+r) g \int_{m_{\min }}^{m_{\max }} \int_{\hat{A}}^{a_{\max }} f(a, m) d a d m= & t_{f} w_{f}^{2} \int_{m_{\min }}^{m_{\max }} \int_{\hat{A}}^{a_{\max }}[1-\pi(a)] f(a, m) d a d m \\
& +t_{p} w_{p}^{2} \int_{m_{\min }}^{m_{\max }} \int_{\hat{A}}^{a_{\max }} \pi(a) f(a, m) d a d m(34)
\end{aligned}
$$

The budget constraint for the graduate tax system can be combined with the process of wage determination to define an equilibrium for the economy. It should be noted that for some pairs of tax rates $\left\{t_{f}, t_{p}\right\}$ there need not be an equilibrium satisfying this definition.

Definition 5 For given tax rates $\left\{t_{f}, t_{p}\right\}$ a balanced budget equilibrium for the economy is a triple $\left\{w_{f}^{2}, w_{p}^{2}, g\right\}$ that satisfy:

$$
\begin{aligned}
w_{f}^{2}= & \frac{\int_{m_{\min }}^{m_{\max }} \int_{\hat{A}}^{a_{\max }} a[1-\pi(a)] f(a, m) d a d m}{\int_{m_{\min }}^{m_{\max }} \int_{\hat{A} \max }^{a_{\max }}[1-\pi(a)] f(a, m) d a d m}, \\
w_{p}^{2}= & \frac{\int_{m_{\min }}^{m_{\max }} \int_{\hat{A}}^{a_{\max }} a \pi(a) f(a, m) d a d m}{\int_{m_{\min }}^{m_{\max }} \int_{\hat{A}}^{a_{\max }} \pi(a) f(a, m) d a d m} ; \\
(1+r) g= & t_{f} w_{f}^{2} \frac{\int_{m_{\min }}^{m_{\max }} \int_{\hat{A}}^{a_{\max }}[1-\pi(a)] f(a, m) d a d m}{\int_{m_{\min }}^{m_{\max }} \int_{\hat{A}}^{a_{\max }} f(a, m) d a d m} \\
& +t_{p} w_{p}^{2} \frac{\int_{m_{\min }}^{m_{\max }} \int_{\hat{A}}^{a_{\max }} \pi(a) f(a, m) d a d m}{\int_{m_{\min }}^{m_{\max }} \int_{\hat{A}}^{a_{\max }} f(a, m) d a d m}
\end{aligned}
$$

\subsection{Basic System}

A very basic graduate tax system would impose a single rate of tax on all people choosing to enter higher education and use the proceeds to finance a grant that exactly matched the cost of education. This system would be described by the conditions $g=c$ and $t_{f}=t_{p}=t$.

The aggregate budget constraint of this graduate tax system is described by

$$
\begin{aligned}
(1+r) g \int_{m_{\min }}^{m_{\max }} \int_{\hat{A}}^{a_{\max }} f(a, m) d a d m= & t w_{f}^{2} \int_{m_{\min }}^{m_{\max }} \int_{\hat{A}}^{a_{\max }}[1-\pi(a)] f(a, m) d a d m \\
& +t w_{p}^{2} \int_{m_{\min }}^{m_{\max }} \int_{\hat{A}}^{a_{\max }} \pi(a) f(a, m) \operatorname{dadm}(38)
\end{aligned}
$$


but since $g=c$

$$
\begin{aligned}
(1+r) c \int_{m_{\min }}^{m_{\max }} \int_{\hat{A}}^{a_{\max }} f(a, m) d a d m= & t\left[w_{f}^{2} \int_{m_{\min }}^{m_{\max }} \int_{\hat{A}}^{a_{\max }}[1-\pi(a)] f(a, m) d a d m\right. \\
& \left.+w_{p}^{2} \int_{m_{\min }}^{m_{\max }} \int_{\hat{A}}^{a_{\max }} \pi(a) f(a, m) d a d m\right] .,(39)
\end{aligned}
$$

This can be solved to write

$$
t=\frac{(1+r) c \int_{m_{\min }}^{m_{\max }} \int_{\hat{A}}^{a_{\max }} f(a, m) d a d m}{\int_{m_{\min }}^{m_{\max }} \int_{\hat{A}}^{a_{\max }}\left(w_{f}^{2}[1-\pi(a)]+w_{p}^{2} \pi(a)\right) f(a, m) d a d m} .
$$

Using this result we have

$$
t w_{f}^{2}=\frac{(1+r) c w_{f}^{2} \int_{m_{\min }}^{m_{\max }} \int_{\hat{A}}^{a_{\max }} f(a, m) d a d m}{\int_{m_{\min }}^{m_{\max }} \int_{\hat{A}}^{a_{\max }}\left(w_{f}^{2}[1-\pi(a)]+w_{p}^{2} \pi(a)\right) f(a, m) d a d m}=(1+r) c \frac{w_{f}^{2}}{\bar{w}},
$$

and

$$
t w_{p}^{2}=\frac{(1+r) c w_{p}^{2} \int_{m_{\min }}^{m_{\max }} \int_{\hat{A}}^{a_{\max }} f(a, m) d a d m}{\int_{m_{\min }}^{m_{\max }} \int_{\hat{A}}^{a_{\max }}\left(w_{f}^{2}[1-\pi(a)]+w_{p}^{2} \pi(a)\right) f(a, m) d a d m}=(1+r) c \frac{w_{p}^{2}}{\bar{w}},
$$

with

$$
w_{f}^{2}<\bar{w} \equiv \frac{\int_{m_{\min }}^{m_{\max }} \int_{\hat{A}}^{a_{\max }}\left(w_{f}^{2}[1-\pi(a)]+w_{p}^{2} \pi(a)\right) f(a, m) d a d m}{\int_{m_{\min }}^{m_{\max }} \int_{\hat{A}}^{a_{\max }} f(a, m) d a d m}<w_{p}^{2} .
$$

The expected utility function when education is chosen is given by

$$
\begin{aligned}
E U^{e} & =U\left(x_{e}^{1}\right)+\delta \pi(a) U\left(w_{p}^{2}+(1+r)\left(m-c \frac{w_{p}^{2}}{\bar{w}}-x_{e}^{1}\right)\right) \\
& +\delta(1-\pi(a)) U\left(w_{f}^{2}+(1+r)\left(m-c \frac{w_{f}^{2}}{\bar{w}}-x_{e}^{1}\right)\right) .
\end{aligned}
$$

Comparing expression (29) for the level of expected utility without the graduate tax to (44) it can be seen that the effect of this graduate tax system, for any given value of $x_{e}^{1}$, is to increase consumption in the fail state and reduce consumption in the pass state. If $\pi(a)=0$, this must lead to an increase in maximum utility for any given value of $m$. By continuity, there will be a range of $a$ for which utility is increased. The same argument applies to initial wealth: the increase in utility will be greatest at low levels of initial wealth.

These arguments can be summarized as a proposition.

Proposition 6 Imposing a uniform graduate tax and providing a grant to cover education costs increases the participation of low-ability individuals and lowwealth individuals in higher education.

This form of graduate tax assists the encouragement of low-wealth individuals into education but has the detrimental effect of also encouraging low-ability individuals who would otherwise choose not to enter higher education. 


\subsection{Differentiated Tax}

We now undertake a numerical analysis of how the graduate tax affects the population choice for education and the equilibrium wage rates when the tax rate can be differentiated and the grant is not tied to the cost of education. In order to assess the efficiency of a graduate tax we compare the outcome under the graduate tax scheme with the constrained first-best outcome. The analysis is undertaken using the same parameter values as in Section 3.

In Table 3 we report the equilibrium wage rates and the level of the grant. The table also reports the index of over-education, $I_{o} \equiv \frac{p_{e}}{p_{f b}}$, and an index of income efficiency $I_{e} \equiv \frac{Y_{m}}{Y_{f b}}$, where $Y_{f b}$ is the present discounted value of income at the constrained first-best (see (20)) and is the present discount value of total income net of education costs at the market equilibrium

$$
\begin{aligned}
Y_{m}= & \frac{2+r}{1+r} \int_{m_{\min }}^{m_{\max }} \int_{a_{\min }}^{\hat{A}} w_{n} f(a, m) d a d m \\
& +\frac{1}{1+r} \int_{m_{\min }}^{m_{\max }} \int_{\hat{A}}^{a_{\max }}\left[\pi(a) w_{p}^{2}+[1-\pi(a)] w_{f}^{2}-[1+r] c\right] f(a, m) d a d m \\
= & \frac{2+r}{1+r} \int_{m_{\min }}^{m_{\max }} \int_{a_{\min }}^{\hat{A}} w_{n} f(a, m) d a d m \\
& +\frac{1}{1+r} \int_{m_{\min }}^{m_{\max }} \int_{\hat{A}}^{a_{\max }}[a-[1+r] c] f(a, m) d a d m
\end{aligned}
$$

The second equality in (45) follows from the definition of equilibrium wage rates.

The results show that an increase in the tax rates raises the equilibrium wages and the level of the grant. The wages rise because participation in education is reduced. This is reflected in the index of over-education which falls as the tax rates rise. Similarly, the index of income efficiency rises with the tax rates. Hence, the introduction of a graduate tax system can improve upon the market outcome. An interesting feature of the table is that the grant, $g$, can exceed the cost of education, $c$. This possibility is forced through the insistence upon a balanced budget for the graduate tax scheme. At the higher rates of tax the revenue collected exceeds the cost of education so provides a surplus that is distributed to those undertaking education through the grant. There is no reason why such a surplus could not be accrued following the practical implementation of a graduate tax system. In welfare terms it may be preferable for at least part of this surplus to be given to those who do not undertake education, but we remain within the tight description of the graduate tax and do not pursue that possibility here. 


\begin{tabular}{|l|l|c|c|c|c|c|}
\hline \multicolumn{2}{|l}{ Scenario } & $w_{f}^{2}$ & $w_{p}^{2}$ & $g$ & $I_{o}$ & $I_{e}$ \\
\hline \multirow{3}{*}{$t_{f}=0$} & $t_{p}=0$ & 0.69356 & 0.78890 & 0 & 1.82126 & 0.83492 \\
\cline { 2 - 7 } & $t_{p}=0.10$ & 0.69373 & 0.78889 & 0.021 & 1.82012 & 0.83505 \\
\cline { 2 - 7 } & $t_{p}=0.15$ & 0.69386 & 0.78904 & 0.03221 & 1.81925 & 0.83515 \\
\hline \hline \multirow{3}{*}{$t_{f}=0.25$} & $t_{p}=0.45$ & 0.69456 & 0.78923 & 0.22300 & 1.81678 & 0.835412 \\
\cline { 2 - 7 } & $t_{p}=0.50$ & 0.69476 & 0.78947 & 0.23397 & 1.81325 & 0.835890 \\
\cline { 2 - 7 } & $t_{p}=0.55$ & 0.69496 & 0.78951 & 0.24478 & 1.81316 & 0.835933 \\
\hline
\end{tabular}

Table 3: Effect of Graduate Tax

The next step is to determine the optimum graduate tax policy. We choose to characterize the optimum policy as the pair $\left\{t_{f}, t_{p}\right\}$ that maximizes net national income, $Y_{m}$. The optimum policy, the resulting equilibrium wages, and the two indices are given in Table 4 . The optimum involves a tax premium for both types (pass and fail) compared to those who choose no education. The grant paid to those in education is in excess of the educational cost. The optimum policy reduces the index of over-education and raises the index of income efficiency relative to the market equilibrium. Judged by these aggregate indicators the graduate tax is a successful policy. However, it is important to stress that this success is achieved because the graduate tax acts to reduce participation in education. This is contrary to the claims made for the graduate tax that it encourages participation.

\begin{tabular}{|l|c|c|c|c|c|c|}
\hline \hline \multicolumn{7}{|c|}{ Optimum } \\
\hline Tax Rates & $w_{f}^{2}$ & $w_{p}^{2}$ & $g$ & $I_{o}$ & $I_{e}$ \\
\hline$t_{f}=0.24$ & $t_{p}=0.53$ & 0.69490 & 0.78951 & 0.23541 & 1.81274 & 0.835973 \\
\hline
\end{tabular}

Table 4: Optimum Tax Structure

The numbers in Table 4 only tell a small part of the story. What is also of interest is how the implementation of the optimum graduate tax system affects the participation in higher education relative to wealth and ability. The effect of the optimum tax structure compared to the market equilibrium is shown in Figure 2. The solid line is the original partition of the population when there is no graduate tax. The dashed line is the partition after the optimum graduate tax system is implemented. The implications of the figure are summarized in a proposition that shows how the optimum graduate tax reinforces the over-education at high wealth levels observed in the market outcome. The explanation for this finding is that the policy focuses on reducing total participation in higher education and does not have the flexibility to distinguish between the low-wealth and the high-wealth. The low-wealth are more easily discouraged from participation so the rather blunt policy of the graduate tax mostly affects their participation.

Proposition 7 The optimum differentiated graduate tax reduces the number of low wealth individuals entering education but increases the number of high-wealth entrants. The positive wealth effect implies that over-education is proportionately worse at high wealth levels. 


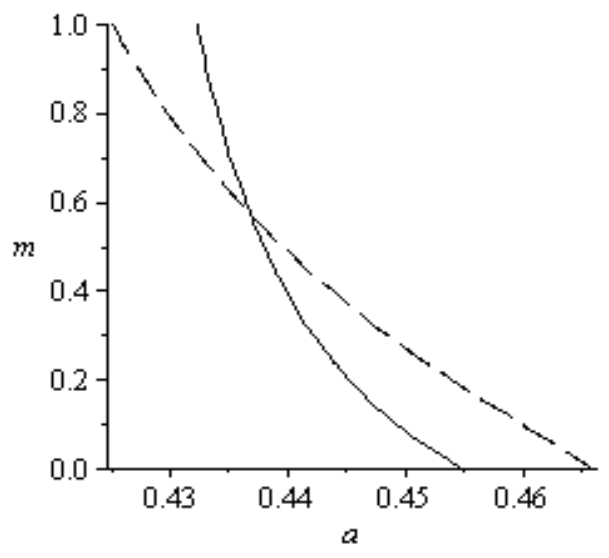

Figure 2: Consequence for participation

The proponents of the graduate tax argue that it will encourage entry into higher education particularly from less privileged groups. The analysis we have conducted shows that, with education as a signal, the converse is true: a graduate tax system encourages participation by the more privileged but discourages the less privileged. The graduate tax may be beneficial when viewed from an aggregate efficiency perspective since it raises net income but this has to be offset against its detrimental distributional consequences.

\section{$5 \quad$ Alternative Structures}

The analysis we have presented has made a number of significant assumptions concerning the information structure, the range of policy interventions, and the nature of the capital market. We now discuss the consequences of modifying a number of these assumptions.

Underlying our analysis has been the assumption that the capital market is perfect. The effect of this assumption is to limit the effect of the graduate tax since it is the most favorable environment for the private financing of education. If we had assumed an imperfect capital the over-education would not be as bad so there would be less efficiency gain from implementing the graduate tax. On the other hand, with an imperfect capital market the distributional consequences of the graduate tax could be even worse. Assume that low-wealth individuals face a higher rate of interest for borrowing than those with high wealth, or more generally that it just is harder for them to borrow to pay education costs. Without a graduate tax the effect of this is clear: it will enhance the positive wealth effect, so the cut-off ability level will increase at low wealth. The implementation of the graduate tax has two off-setting effects. The grant will help ease some of the problems caused by the imperfect capital market which will encourage entry into education by those with low wealth. Conversely, the taxes 
in the second-period will still cause the cut-off line to pivot which will reduce the entry of low-wealth individuals into education. If the latter effect dominates the graduate tax will still have negative distributional effects on participation.

The graduate tax we have modelled is more general than many actual proposals but remains restricted in its flexibility. It is natural to consider what would happens if a more general nonlinear structure of taxation were adopted. In the present context this would not improve the functioning of the graduate tax. The reasoning behind this claim is that the inefficiency is due to the process of signalling and this would not be changed by a nonlinear tax. In addition, the distributional issues arise due to the non-observability of initial wealth, and a nonlinear income tax will have not aid in this respect. Moreover, within the context of the model there are only two income levels, so two tax rates are sufficiently general when the range of incomes is so limited. An alternative policy would be to use the graduate tax to provide a payment to the non-educated. This will reduce the attractiveness of higher education and reduce the excess entry. However, doing this would move beyond the proposed self-financing structure of the graduate tax.

We have adopted an information structure that permits neither the government nor the firms to observe ability or the initial level of wealth. We now briefly describe two alternative possibilities, each with implications for the graduate tax. First, assume the government can observe ability but not wealth, the firms can observe neither, and the government cannot credibly convey ability information to firms. In this case the government can implement the constrained first-best by using observed ability to ration access to education. This will work because the market equilibrium has over-education for all wealth levels. Hence, a graduate tax is not necessary in this scenario. Second, assume the government can observe wealth but not ability. Then the solution is to remove the wealth differential by redistribution and use the graduate tax to push the cut-off ability level toward the constrained first-best point. The degree of efficiency that can be attained is still constrained by the signalling effect of education.

\section{Conclusions}

The graduate tax has been proposed as a method of funding higher education that encourages participation, especially by the less privileged. This argument may have some validity if the return to higher education arises from the accumulation of human capital. On the other hand, if the return is due to signalling then the argument is much less compelling.

We consider the graduate tax in the context of an educational choice model with signalling and uncertainty. The uncertainty occurs because the outcome of higher education is unknown at the point the entry decision is made. The return to education is determined via signalling with education used by employers to screen people according to their unobserved ability. Education does not add to human capital and plays no role in enhancing productivity. Assuming heterogeneity in terms of ability and initial wealth our results show that the 
uncertainty creates a positive wealth effect so the cut-off level of ability for entry into higher education declines with wealth level. Furthermore, at the market equilibrium there is excessive entry into higher education compared to the constrained first-best level. The introduction of a graduate tax reduces entry into education which enhances efficiency. However, the graduate tax has the undesirable distributional consequence of deterring low-wealth individuals from entering education but encouraging high-wealth individuals. In this respect, the graduate tax clearly fails as a method of financing higher education.

The graduate tax has been proposed as a way of overcoming the deterrent effect that imperfect capital markets and uncertainty have on entry into higher education by the less privileged. This is achieved by providing partial insurance against a poor educational outcome and by spreading the costs of education over the working life so avoiding significant up-front costs. These arguments seem compelling but their validity requires careful examination. We have embedded the graduate tax within a model of educational choice with signalling and found that the claims made by its proponents are not met. The graduate tax increases economic efficiency by reducing excessive entry into higher education but does this by discouraging the less privileged. In this situation the graduate tax is not the solution to the limited participation of the less privileged in higher education.

\section{Appendix}

Proof of proposition 1.

The first step is to determine the effect of the introduction of risk upon first period consumption. Denote the choice of first-period consumption arising from (10) by $x_{e}^{1}\left(m, a ; w_{f}^{2}, w_{p}^{2}\right)$. Changes in $w_{f}^{2}$ and $w_{p}^{2}$ that maintain constant utility satisfy

$$
\begin{gathered}
U\left(x_{e}^{1}\left(m, a, w_{f}^{2}, w_{p}^{2}\right)\right)+\pi(a) \delta U\left([1+r]\left[m-c-x_{e}^{1}\left(m, a, w_{f}^{2}, w_{p}^{2}\right)\right]+w_{p}^{2}\right) \\
\quad+[1-\pi(a)] \delta U\left([1+r]\left[m-c-x_{e}^{1}\left(m, a, w_{f}^{2}, w_{p}^{2}\right)\right]+w_{f}^{2}\right)=0
\end{gathered}
$$

Taking the total differential of (46) and using the envelope condition

$$
\frac{d w_{f}^{2}}{d w_{p}^{2}}=-\frac{\pi(a) U^{\prime}\left(x_{p}^{2}\right)}{[1-\pi(a)] U^{\prime}\left(x_{f}^{2}\right)} .
$$

Totally differentiating (10) and using the envelope condition again gives

$$
\begin{gathered}
d x_{e}^{1}\left[\frac{U^{\prime \prime}\left(x_{e}^{1}\right)}{1+r}+\pi(a) \delta(1+r) U^{\prime \prime}\left(x_{p}^{2}\right)+[1-\pi(a)] \delta(1+r) U^{\prime \prime}\left(x_{f}^{2}\right)\right] \\
-d w_{p}^{2}\left[\pi(a) \delta U^{\prime \prime}\left(x_{p}^{2}\right)+[1-\pi(a)] \delta U^{\prime \prime}\left(x_{f}^{2}\right) \frac{\partial w_{f}^{2}}{\partial w_{p}^{2}}\right]=0 .
\end{gathered}
$$


But using (47)

$$
\frac{d x_{e}^{1}}{d w_{p}^{2}}=\frac{\pi(a) \delta U^{\prime}\left(x_{p}^{2}\right)\left[\frac{U^{\prime \prime}\left(x_{p}^{2}\right)}{U^{\prime}\left(x_{p}^{2}\right)}-\frac{U^{\prime \prime}\left(x_{f}^{2}\right)}{U^{\prime}\left(x_{f}^{2}\right)}\right]}{\frac{U^{\prime \prime}\left(x_{e}^{1}\right)}{1+r}+\pi(a) \delta(1+r) U^{\prime \prime}\left(x_{p}^{2}\right)+[1-\pi(a)] \delta U^{\prime \prime}\left(x_{f}^{2}\right)} .
$$

Since $w_{p}^{2}>w_{f}^{2}$ it follows that $x_{p}^{2}>x_{f}^{2}$. Decreasing absolute risk aversion then implies that

$$
\frac{U^{\prime \prime}\left(x_{p}^{2}\right)}{U^{\prime}\left(x_{p}^{2}\right)}-\frac{U^{\prime \prime}\left(x_{f}^{2}\right)}{U^{\prime}\left(x_{f}^{2}\right)}>0 .
$$

Since the denominator of (48) is negative it follows (49) that $\frac{d x_{e}^{1}}{d w_{p}^{2}}<0$ which shows that an increase in risk with constant expected utility reduces first-period consumption.

Applying the envelope theorem, the total derivative of the indifference condition (15) is

$$
\begin{aligned}
0= & d m\left[\delta[1+r]\left[\pi(a) U^{\prime}\left(x_{p}^{2}\right)+[1-\pi(a)] U^{\prime}\left(x_{f}^{2}\right)-U^{\prime}\left(x_{n}^{2}\right)\right]\right] \\
& +d a\left[\pi^{\prime} \delta\left[U\left(x_{p}^{2}\right)-U\left(x_{f}^{2}\right)\right]\right] .
\end{aligned}
$$

Given $\pi^{\prime}>0$ and $w_{p}^{2}>w_{f}^{2}$ it is clear that $\pi^{\prime} \delta\left[U\left(x_{p}^{2}\right)-U\left(x_{f}^{2}\right)\right]>0$. From the first-order conditions (4) and (10)

$$
\delta[1+r]\left[\pi(a) U^{\prime}\left(x_{p}^{2}\right)+[1-\pi(a)] U^{\prime}\left(x_{f}^{2}\right)-U^{\prime}\left(x_{n}^{2}\right)\right]=U^{\prime}\left(x_{e}^{1}\right)-U^{\prime}\left(x_{n}^{1}\right) .
$$

The first part of the proof implies $x_{n}^{1}>x_{e}^{1}$, so $U^{\prime}\left(x_{n}^{1}\right)-U^{\prime}\left(x_{e}^{1}\right)>0$. Combining these observation demonstrates that $\frac{d m}{d a}<0$, so $\alpha\left(m, w_{f}^{2}, w_{p}^{2}\right)$ is strictly monotonically decreasing in $m$.

With constant absolute risk aversion $\frac{U^{\prime \prime}\left(x_{p}^{2}\right)}{U^{\prime}\left(x_{p}^{2}\right)}-\frac{U^{\prime \prime}\left(x_{f}^{2}\right)}{U^{\prime}\left(x_{f}^{2}\right)}=0$ and with increasing absolute risk aversion $\frac{U^{\prime \prime}\left(x_{p}^{2}\right)}{U^{\prime}\left(x_{p}^{2}\right)}-\frac{U^{\prime \prime}\left(x_{f}^{2}\right)}{U^{\prime}\left(x_{f}^{2}\right)}<0$. The claims in the statement then follow directly.

Proof of proposition 3.

Let $a^{c}$ be the cut-off level of ability in the case of certainty $(\pi(a)=1$, all a) when each person is paid their private marginal product. Denote the wage received by a person with cut-off level of ability by $w_{c}^{2}=a^{c}$. Under these conditions $a^{c}$ does not depend on $m$. So, from (21) it follows that $a^{c}=a^{*}$.

Now retain certainty and introduce signalling. Assume the cut-off remains at $a^{c}$. The wage received is the mean marginal product of the educated so $w_{p}^{2}>w_{c}^{2}$. But $a^{c}$ cannot then be the cut-off since a person of that ability will now strictly prefer to choose education. Hence, there is excess entry into education and $a^{0}>a^{c}$. 
Finally, introduce uncertainty. Begin with the cut-off at $a^{c}$. It is now the case that for an individual with ability $a^{c}$ the payoff in both states of the world is above their marginal product: $w_{p}^{2}>w_{c}^{2}$ and $w_{f}^{2}>w_{c}^{2}$. Hence, they cannot be indifferent between education and no education. This argument holds irrespective of $m$.

\section{References}

1. Becker, G.S. (1964) Human Capital, New York: Columbia University Press for the National Bureau of Economic Research.

2. Bell, E.B. (1984) "Imperfect capital markets and investment in education", Economics of Education Review, 3, 105 - 110.

3. Ben-Porath, Y. (1967) "The production of human capital and the life cycle of earnings", Journal of Political Economy, 75, 352 - 365 .

4. Eaton, J. and Rosen, H. (1980) "Taxation, human capital and uncertainty", American Economic Review, 70, $705-715$.

5. García-Peñalosa, C., and Walde, K. (2000) "Efficiency and equity effects of subsidies to higher education", Oxford Economic Papers, 52, $702-722$.

6. Glennerster, H. (2003) "A graduate tax revisited", Higher Education Review, 35, $25-26$.

7. Glennerster, H., Merret, S. and Wilson, G. (2003) "A graduate tax", Higher Education Review, 35, 27 - 40.

8. Kodde, D.A. (1986). "Uncertainty and the demand for education", Review of Economics and Statistics, 68, $460-467$

9. Levhari, D. and Weiss, Y. (1974) "The effect of risk on the investment in human capital", American Economic Review, 64, 950 - 963.

10. Snow, A. and Warren, R. (1990) "Human capital investment and labor supply under uncertainty", International Economic Review, 31, 195 - 206.

11. Spence, M. (1973) "Job market signaling", Quarterly Journal of Economics, 87, $355-374$.

12. Weiss, A. (1995) "Human capital vs. signalling explanations of wages", Journal of Economic Perspectives, 9, 133 - 154. 